\title{
Safety signals can mimic responses in reducing the ulcerogenic effects of prior shock
}

\author{
J. BRUCE OVERMIER, ROBERT MURISON, EVEN JARL SKOGLUND, and HOLGER URSIN \\ Institute of Physiological Psychology, University of Bergen, Norway
}

\begin{abstract}
The severity of restraint-induced gastric ulcerations in rats may be influenced by proactive effects of earlier shock experience. Earlier experience with escapable shock offers some protection against the ulcerogenic effects of restraint stress. In this experiment, we tested the hypothesis that providing animals with safety signals during a Pavlovian conditioning session would also provide a proactive protection against restraint ulceration similar to that provided by escape responses. Animals were subjected to five daily sessions of 20 shocks before they were subjected to a single $23-\mathrm{h}$ restraint stress procedure. The animals given safety signals during the conditioning sessions developed less ulceration than those subjected to random tone-shock pairings and those that were not shocked. This complements other reports of the similar properties shared by escape conditioning and safety-signal (backward) conditioning. In contrast, postrestraint corticosterone levels were higher in animals provided earlier with safety signals than they were in other groups.
\end{abstract}

Stress-related gastric ulceration has been the focus of many studies seeking to elucidate the role of psychological factors in physical health and well-being (Miller, 1979; Tsuda \& Hirai, 1977; Weiner, 1977; Weiss, 1977). A number of studies have concentrated on the role of predictability of an aversive event (e.g., shock) in stress-induced ulceration (Gliner, 1972; Seligman \& Meyer, 1970; Weiss, 1970); others have concentrated on the role of controllability of the aversive stimuli (Barbaree \& Harding, 1973; Tsuda \& Hirai, 1977; Weiss, 1968) or other possible coping responses (Ackerman, 1980; Guile \& McCutcheon, 1980; Mawson, 1978). For example, Weiss (1971) demonstrated that rats exposed to a long, continuous escape/avoidance task developed less ulceration and showed smaller increases in plasma corticosterone than did animals that had no escape or avoidance contingency available, and that signaling the avoidable shock further reduced ulceration, possibly by making the responding more closely associated with shock elimination.

The bulk of such studies have focused upon the effects of these psychological manipulations during relatively short (single session) presentations of one type of stressor. But life is a stream of events that occur over longer periods of time (i.e., days) rather than just during these acute periods which are only a few hours long; moreover,

This research was supported by the Norwegian Research Council for Science and the Humanities (NAVF). J. B. Overmier is presently at the Department of Psychology, University of Minnesota. His participation in this research was supported in part by a fellowship from the J. E. Fogarty International Center for Advanced Study in the Health Sciences (FO-TW00976), and awards from the James McKeen Cattell Foundation and the Bush Foundation. The authors wish to thank Randi Espelid and Axel Robinson for their technical assistance. Requests for reprints should be sent to J. B. Overmier, Department of Psychology, Elliott Hall, 75 East River Road, Minneapolis, MN 55455. successive occasions of stress are rarely the same. There have been a few investigations into the proactive effects of one type of stressor upon the ulcerative effects of a delayed second stressor (e.g., Weinberg, Erskine, \& Levine, 1980), but not many, except within a developmental framework (e.g., Ackerman, 1980; Boyd, Caul, \& Bowen, 1977; Sines, Patterson, \& Rusch, 1977).

Murison and Isaksen (1982, Experiment 2), however, have shown that rats may be sensitized to or protected from the ulcerogenic effects of one stressor, restraint, by earlier exposure to a different stressor, shock. Moreover, which effect obtains is determined not by the shocks per se, but by whether the shocks were controllable or uncontrollable-that is, by a "psychological" difference in the shocks, not a physical one. The severity of gastric ulceration and the amount of adrenocortical system output due to restraint stress were less in rats that had first experienced escapable shocks than they were in rats that had received no prior shocks, which in turn showed less response than rats that had received matched prior inescapable shocks.

Considerable attention has been given to the role of control in the modulation of the proactive effects of stressors on behavior (e.g., Overmier \& Seligman, 1967; Seligman, 1975; Seligman \& Maier, 1967) and on corticoid responsivity (e.g., Dess, Linwick, Patterson, Overmier, \& Levine, 1983), and Murison and Isaksen's results are consistent with this emphasis. Here, however, we want to consider an alternative view-one that emphasizes signals rather than responses.

The escape paradigm requires that animals make a specific distinctive response to terminate a shock. Because, in the Murison and Isaksen experiment, there was a fixed intertrial interval of $20 \mathrm{sec}$, responses terminating shocks could also have functioned as signals for a 
period of safety, as well as providing control (Moscovitch \& LoLordo, 1968; Seligman, 1968). That is, a response could be an analogue to a "safety signal" as occurs when employing the backward or inhibitory conditioning paradigm (see LoLordo \& Fairless, 1985). That signaled shocks are less ulcerogenic than unsignaled shocks (Fife, 1970; Weiss, 1970, 1971) and lead to smaller increases in plasma corticosterone (Bassett \& Cairncross, 1973) may be because the absence of the warning danger signal is itself a cue for safety (see Seligman, 1968).

Indeed, backward conditioning, or the presentation of safety signals, does result in lower corticosterone secretion in a Pavlovian conditioning design than does unpredictable shock or random CS/UCS presentations (Hennessy, King, McClure, \& Levine, 1977). More importantly for the present purposes, Starr and Mineka (1977, Experiment 2) and Mineka, Cook, and Miller (1984), who compared animals with control over shocks with two yoked groups without control, one with a backward CS or safety signal at the end of each shock and one without such signals, found that the animals in the yoked group with neither control nor backward CSs were more fearful than those with control and than those with backward CSs, and that the latter two groups did not differ in fearfulness. And in a conceptually similar study, Volpicelli, Ulm, and Altenor (1984) found that only the yoked group with no safety signal showed proactive interference with later coping behaviors in a new shock-escape task. These studies suggest that the critical factor in all such experiments may not be control over shock per se, but rather the safety cuing function afforded by the feedback from the responses.

Because there appear to be similarities between the effects of escape responses and backward-conditioned safety signals on behavior, fear, and adrenocortical activity, our present experiment was designed to explore whether previous experience with shocks accompanied by backward-conditioned safety signals would, as opposed to experience with identical shocks in the absence of safety signals, result in similar proactive ulcer-reducing effects on restraint-induced ulceration as had earlier been shown for escape (Murison \& Isaksen, 1982, Experiment 2). Our hypothesis was that presenting a signal at the end of inescapable shocks would reduce the proactive ulcerogenic effects of these shocks, similar to the way in which the escape response had been shown to reduce restraintinduced ulcerogenesis. To facilitate comparison of the effects obtained in each, the present experiment reproduced the procedures and parameters of Murison and Isaksen's (1982) experiment.

\section{METHOD}

\section{Subjects}

The subjects were 27 naive male Sprague-Dawley rats, approximately 120 days old at the time of the experiment. The animals were purchased from Anticimex (Sweden) and were housed singly for 4 weeks before the start of the study. The animals were housed in a temperature- $\left(22^{\circ}\right)$ and humidity-regulated animal room, with free access to food and water. Before the experiment, the animals were regularly handled and weighed. The animals were assigned to one of three groups, matched for body weight. Nine animals were allocated to a backward conditioning (BC) group (mean weight $417.3 \mathrm{~g}$ ), 9 to a truly random control (TRC) group (mean weight $415.9 \mathrm{~g}$ ), and 9 to a nonshock (NS) control condition (mean weight $417.1 \mathrm{~g})$.

\section{Apparatus}

Conditioning phase. Pavlovian conditioning took place in an apparatus that allowed for delivery of footshock to up to 15 animals simultaneously. The apparatus consisted of 15 chambers, each $20 \mathrm{~cm}$ long, $6.6 \mathrm{~cm}$ wide, and $9 \mathrm{~cm}$ high. The top of each chamber was covered by a clear acrylic door. The sides and bottoms of each chamber were made of two L-shaped pieces of aluminum, the longer arm $(9 \mathrm{~cm})$ forming the side of the chamber and the shorter arm $(2.2 \mathrm{~cm})$ forming part of the floor. The chamber floor was thus composed of two aluminum strips separated by $2.2 \mathrm{~cm}$. The chambers were mounted $10 \mathrm{~cm}$ above the bench, so that each animal was forced to sit or stand with two feet on each strip, or electrode. Each electrode was connected in series to one of the electrodes in an adjacent chamber. The apparatus was constructed such that a number of animals could receive shock simultaneously, while a predetermined number of animals remained unshocked. Shock was delivered via a Lafayette constant current shocker (58006) with an extra 1-M $\Omega$ resistor placed in series between the shocker and the shock chambers, bringing the total series' resistance in the shock circuit to a $1.45-\mathrm{M} \Omega$ minimum. Current level was always $1 \mathrm{~mA}$.

The CS consisted of a $1-\mathrm{kHz}$ tone at $60 \mathrm{~dB}$, measured at the top of the shock chamber, generated by a Jostykit generator and amplifier. The CS was delivered through a speaker mounted $1 \mathrm{~m}$ above the shock apparatus. Shock and tone delivery were controlled by Lehigh Valley interfaces coupled to a TRS-80 microcomputer.

Restraint phase. For the restraint phase, animals were placed in plastic tubes, $17.5 \mathrm{~cm}$ long and $6 \mathrm{~cm}$ in diameter (internal measurements). The tubes were closed at each end by two metal bolts. The tubes were perforated with $128-\mathrm{mm}$ holes that were placed equidistantly $(7 \mathrm{~cm})$ from each other in three rows. The animals were able to make some minor movements within the tubes and also to bite the securing bolts. The tubes were placed in a rack at an angle of $25^{\circ}$ relative to the floor with the animal's head up. The restraint procedures were performed in a temperature-controlled room $\left(19^{\circ} \mathrm{C}\right)$ under continuous red lighting.

\section{Procedure}

Conditioning phase. The animals were exposed to five conditioning sessions on 5 consecutive days. On Day 1 and Day 5, blood samples were drawn from all animals approximately $18 \mathrm{~min}$ after the last conditioning trial. The animals remained in the conditioning apparatus during this interval. Blood was drawn from the jugular vein exposed under ether anesthesia within 3 min following the animal's removal from the conditioning apparatus. Approximately $0.8 \mathrm{ml}$ blood was collected into a heparinized syringe and then centrifuged for $25 \mathrm{~min}$; the plasma was frozen. Samples were later analyzed fluorometrically, using a modified version of the technique described by Glick, von Redlich, and Levine (1964).

On each conditioning day, animals of the BC and TRC groups were exposed to 20 shocks, with an onset-to-offset interval of $40 \mathrm{sec}$. For the BC animals, each shock was followed by the presentation of a 10 -sec tone (CS). For the TRC animals, the tone was presented in a random fashion, independently of the scheduled shocks. The duration of shock on a given trial on a given day was computed from the escape latency data of Murison and Isaksen (1982), so that our animals were subjected to approximately the same total shock, shock durations, and variance as those in the escape paradigm. Mean shock durations over the 20 trials of each of the five conditioning days were $2.5,1.9,2.0,1.7$, and $3.9 \mathrm{sec}$. Animals 
of the NS group were also placed in the conditioning apparatus, and the CS (tone) was delivered. These animals, however, received no shock.

Restraint phase. One week after the last conditioning session, all animals were rehoused in wire-bottom cages and deprived of food. Water remained available. Forty hours later, the animals were placed in the restraint apparatuses described above. The animals remained restrained for $20 \mathrm{~h}$, at which time they were anesthetized and killed by decapitation within 3 min of removal from the apparatus. Trunk blood was collected, centrifuged, and frozen for later corticosterone analysis (see above).

To assess the degree of gastric ulceration, the stomach was removed and cut along the lesser curvature. The assessment of each stomach was performed by an experienced investigator, who was blind as to which group the animal came from. Visual examination was made of each stomach under a $2 \times$ magnifying lens, and scores were made of the number and lengths of any gastric erosions.

\section{RESULTS}

The data from each measure in each phase were subjected to an ANOVA, and contrasts were based upon these ANOVAs.

The different treatment conditions resulted in differing levels of adrenocortical activity on both the 1st and 5th conditioning day $[\mathrm{F}(2,24)=12.3$ and 20.1 , respectively, $\mathrm{p}<.01$; Figure 1]. These differences arose, however, only from differences between shock (BC and TRC) and nonshock (NS) conditions $[\mathrm{t}(24)=4.9$ and 7.9 , respectively]. The two aversive conditioning procedures (BC and TRC) themselves did not lead to differences in corticosterone on either sampling day [ $\mathrm{t}(24)=0.1$ and 1.6 , respectively]. Corticosterone levels in all groups were lower on the last conditioning day than on the first $[F(1,24)=7.9$, $\mathrm{p}<.01]$, and there were no differences in this pattern between groups $[\mathrm{F}(2,24)<1]$.

The major dependent variable in this study, gastric ulceration, did show differences over groups. Gastric ulcerations were observed only in the glandular portion of the stomach. Lengths of gastric ulceration did not differ

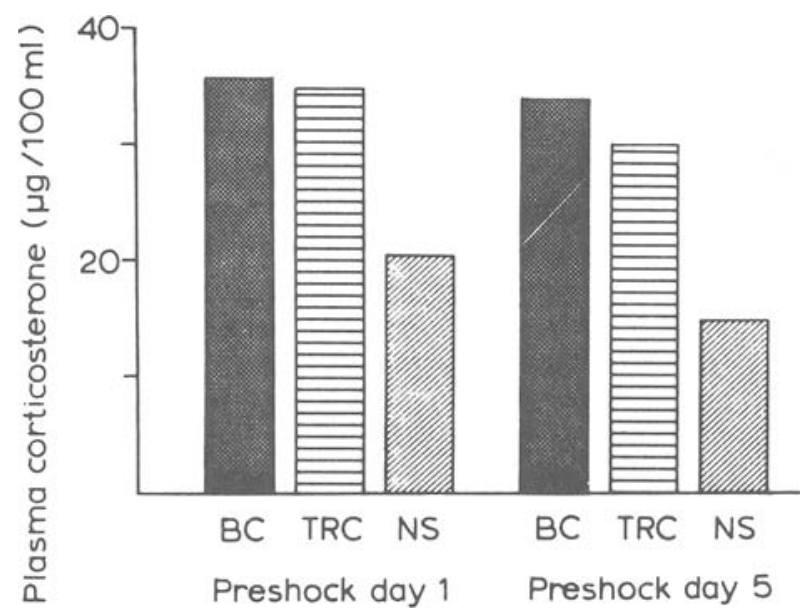

Figure 1. Mean group plasma corticosterone concentrations after first and last of five daily conditioning sessions ("preshock days").

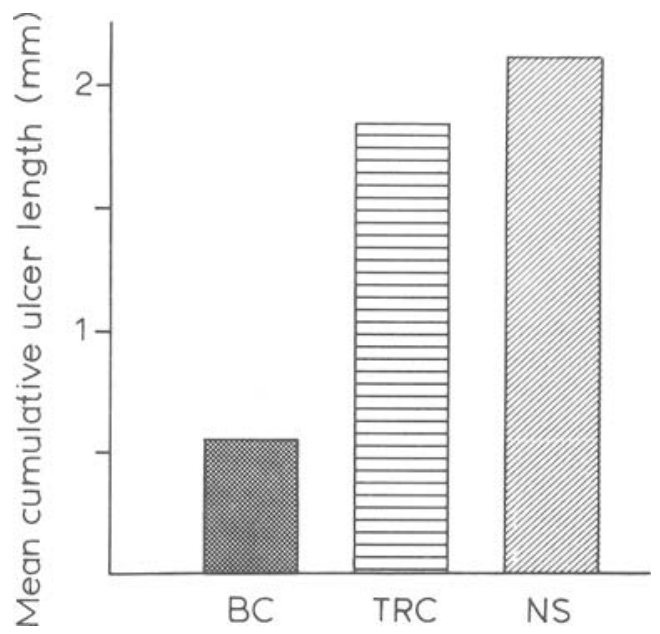

Figure 2. Mean cumulative lengths of gastric ulceration for each group after $23 \mathrm{~h}$ of restraint stress.

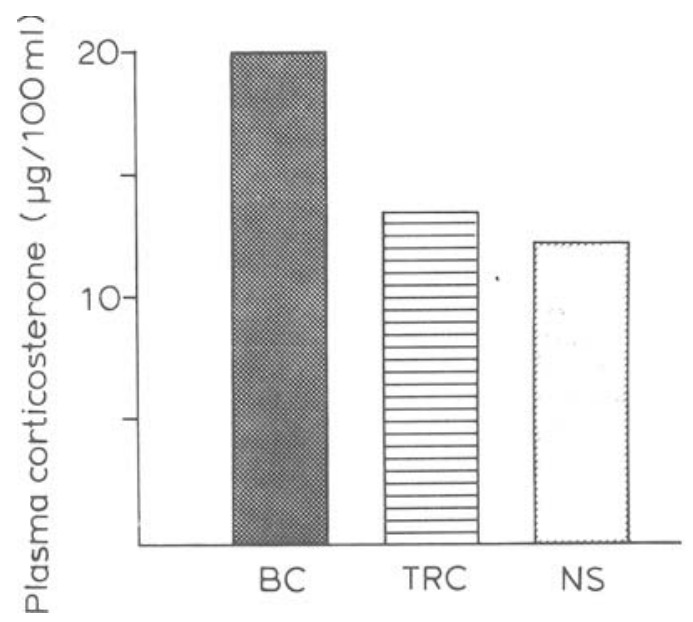

Figure 3. Mean plasma corticosterone concentrations for each group after $23 \mathrm{~h}$ of restraint stress.

between the TRC and NS groups [t $(24)<1]$. Animals subjected to the backward-conditioning treatment (BC) exhibited less gastric ulceration than the other two (TRC and NS) groups (Figure 2), in line with our starting hypothesis and expectations based upon Murison and Isaksen's $(1982)$ results $[t(24)=1.8, p<.05$, one-tailed].

In contrast to the ulceration data, the corticosterone data indicated that, at the end of the restraint-stress period, $\mathrm{BC}$ animals exhibited higher corticosterone levels than either the TRC group or the NS group $[\mathrm{t}(24)=2.1$ and 2.5 , respectively (Figure 3 ), both $\mathrm{p}<.05$, two-tailed]. Corticosterone levels at this point did not differ between the TRC and NS groups [ $t(24)<1]$. Finally, we computed the degree of correlation between the extent of ulceration and level of postrestraint corticosterone. This correlation was -.01 , n.s. 


\section{DISCUSSION}

The pattern of results on ulcerogenesis in this experiment, in which signals were presented at the end of shocks, parallels that previously obtained by Murison and Isaksen (1982), where responses terminated shocks. In the present experiment, animals with signals at the end of shocks showed less gastric ulceration under later restraint stress than did those animals that received exactly the same shocks but without safety signals; in the Murison and Isaksen study, animals responding to end shocks showed less ulceration under later restraint stress than did animals that received exactly the same shocks (yoked) but for which their responses did not terminate the shocks. In the two experiments, all animals received essentially the same total amount of shock, the same number of shocks, and the same daily distributions of shock durations with the same variability. From this we conclude that safety signals can mimic responses in reducing the proactive ulcerogenic effects of shocks.

Many investigators have emphasized the role of control over stressful events in ameliorating the consequences of those stressors (e.g., Anisman, Pizzino, \& Sklar, 1980; Coover, Ursin, \& Levine, 1973; Glass \& Singer, 1972; Seligman, 1975). And the importance of control has been amply demonstrated (see Maier \& Seligman, 1976, for one review). What has been at issue is the mechanism through which control leads to reduced consequences from the stressor (Averill, 1973; Miller, 1979; Mowrer \& Viek, 1948; Seligman, 1975). Some have argued that the mechanism is the signaling of safety (Seligman, 1968). The empirical finding here is consistent with arguments like those of Seligman (1968), which emphasized the importance of the signal properties of responses that terminate stressors. In this, then, the present results contribute to the accumulating body of data using similar experimental designs in purely behavioral experiments (Mineka et al., 1984; Starr \& Mineka, 1977; Volpicelli et al., 1984). The present research extends this body of information to the domain of psychosomatic relevant gastric ulceration.

The present results do differ from those of Murison and Isaksen (1982) in one important way. Murison and Isaksen reported that the postrestraint corticosterone levels for rats which previously could control shocks through their escape responses were reduced relative to those of the yoked animals. In contrast, we found postrestraint corticosterone levels for rats for which safety signals accompanied the termination of shocks (in place of responses) to be increased relative to those of the matched-shocked (TRC) animals. This suggests that although coping behaviors may result in a general positive transfer, safety signals might result in more limited, specific effects, not all of which may be positive proactively and, as found here with corticosterone reactivity, may even be "negative", 1

The present results also differ from a conceptually similar experiment by Fife (1970). In Fife's experiment, how- ever, the signal associated with the end of the shock actually began during the fixed-duration shocks and terminated with shocks. This procedure (sometimes called cessation conditioning) - using shocks of fixed durationhas been demonstrated by others (e.g., Moscovitch \& LoLordo, 1968) not to be effective for establishing safety signals and also to allow for the possibility of simultaneous excitatory conditioning (Heth \& Rescorla, 1973).

Finally, some comment is required on the obtained degrees of correlation between ulceration and postrestraint corticosterone. The obtained correlation was essentially zero, and this differs from other results reported in the literature. This may arise from at least two possibilities. One is that all groups in our experiment were stressed, and all manifested ulceration, whereas other computations may have been based upon a mixture of stressed and unstressed controls, thus artifactually leading to a positive correlation. The second is that our procedure was one involving a sequence of stressors in which the initial treatment may have modulated one feature of the subject's response to the later stressor (gastric processes) but not another (adrenocortical processes), or may even have modulated them in different directions. Very little is understood about the serial conditions that lead to adaptation or sensitization in various physiological systems (Weiss, Glazer, Pohorecky, Brick, \& Miller, 1975; Zigmond \& Harvey, 1970). What is clear from the present correlation is that degree of ulceration can show a substantial degree of independence from corticosterone levels, suggesting that they do not have a single common causal origin, nor are they sequentially causally related to one another. In sum, although safety signals can mimic escape responses in reducing the proactive ulcerogenic effects of shocks, they do not necessarily do so with respect to adrenocortical activity.

\section{REFERENCES}

Ackerman, S. H. (1980). Early life events and peptic ulcer susceptibility: An experimental model. Brain Research Bulletin, 5(Suppl. 1), 43-49.

Anisman, H., Pizzino, A., \& Sklar, L. S. (1980). Coping with stress, norepinephrine depletion and escape performance. Brain Research, 191, 583-588.

Averill, J. R. (1973). Personal control over aversive stimuli and its relationship to stress. Psychological Bulletin, 80, 286-310.

BarbareE, H. E., \& HARDING, R. K. (1973). Free-operant avoidance behavior and gastric ulcerations in rats. Physiology \& Behavior, 11, 269-271.

Bassett, J. R., \& Cairncross, K. D. (1973). Parameters of novelty, shock predictability and response contingency and corticosterone release in the rat. Physiology \& Behavior, 10, 901-907.

Boyd, S. C., Caul, W. F., \& Bowen, B. K. (1977). Use of cold restraint to examine psychological factors in gastric ulceration. Physiology \& Behavior, 18, 865-870.

Coover, G. D., Ursin. H., \& Levine, S. (1973). Plasma corticosterone levels in rats during active-avoidance learning. Journal of Comparative \& Physiological Psychology, 82, 170-174.

Dess, N. K., Linwick, D., Patterson, D., Overmier, J. B., \& LeVINE, S. (1983). Immediate and proactive effects of controllability and predictability on plasma cortisol responses to shocks in dogs. $\mathrm{Be}$ havioral Neuroscience, 97, 1005-1016. 
FIFE, D. (1970). The effects of stimuli associated with shock onset or termination on restraint-induced gastric lesions. Psychonomic Science, 19, 163-164.

Glass, D. C., \& Singer, J. E. (1972). Urban stress: Experiments on noise and social stressors. New York: Academic Press.

Glick, D., von Redlich, D., \& Levine, S. (1964). Fluorometric determination of corticosterone and cortisol in 0.02-0.05 millilitres of plasma or submilligram samples of adrenal tissue. Endocrinology, 74, 653-655.

Gliner, J. A. (1972). Predictable vs. unpredictable shock: Preference behavior and stomach ulceration. Physiology \& Behavior, 9, 693-698.

Guile, M. N., \& MCCutcheon, N. B. (1980). Prepared responses and gastric lesions in rats. Physiological Psychology, 8, 480-482.

Hennessy, J. W., King, M. G., McClure, T. A., \& Levine, S. (1977). Uncertainty, as defined by the contingency between environmental events, and the adrenocortical response of the rat to electric shock. Journal of Comparative \& Physiological Psychology, 91, 1447-1460.

HeTh, C. D., \& Rescorla, R. A. (1973). Simultaneous and backward fear conditioning in the rat. Journal of Comparative \& Physiological Psychology, 82, 434-443.

LoLordo, V. M., \& Fairless, J. (1985). Pavlovian conditioned inhibition: The literature since 1969. In R. R. Miller \& N. E. Spear (Eds.), Information processing in animals: Inhibition and contingencies. Hillsdale, NJ: Erlbaum.

Maier, S. F., \& Seligman, M. E. P. (1976). Learned helplessness: Theory and evidence. Journal of Experimental Psychology: General, $105,3-46$.

Mawson, A. R. (1978). Attenuating effect of fighting on shock-induced gastric ulceration and hypertension: Hypothesis of inhibition by sensory feedback. Medical Hypotheses, 4, 403-410.

Miller, N. E. (1979). Effects of learning on physical symptoms produced by psychological stress. In H. Selye (Ed.), Guide to stress research. New York: Van Nostrand.

MineKa, S., Cook, M., \& Miller, S. (1984). Fear conditioned with escapable and inescapable shock: Effects of a feedback stimulus. Journal of Experimental Psychology: Animal Behavior Processes, 10, 307-323.

Moscovitch, A., \& LoLordo, V. M. (1968). Role of safety in the Pavlovian backward fear conditioning procedure. Journal of Comparative \& Physiological Psychology, 66, 673-678.

MoWReR, O. H., \& VIEK, P. (1948). An experimental analogue of fear from a sense of helplessness. Journal of Abnormal \& Social Psychology, 83, 193-200.

MURISON, R., \& ISAKSEN, E. (1982). Gastric ulceration and adrenocortical activity after inescapable and escapable pre-shock in rats. Scandinavian Journal of Psychology, Suppl. 1, 133-137.

Overmier, J. B., \& Seligman, M. E. P. (1967). Effects of inescapable shock upon subsequent escape and avoidance learning. Journal of Comparative \& Physiological Psychology, 63, 23-33.

Seligman, M. E. P. (1968). Chronic fear produced by unpredictable electric shock. Journal of Comparative \& Physiological Psychology, 66, 402-411.

Seligman, M. E. P. (1975). Helplessness: On depression, development, and death. San Francisco: Freeman.

Seligman, M. E. P., \& Maier, S. F. (1967). Failure to escape traumatic shock. Journal of Experimental Psychology, 74, 1-9.
Seligman, M. E. P., \& Meyer, B. (1970). Chronic fear and ulcers as a function of the unpredictability of safety. Journal of Comparative \& Physiological Psychology, 73, 202-207.

Sines, J. O., Patterson, K., \& Rusch, L. (1977). The experimental production of resistance to stress-induced stomach lesions in the rat. Journal of Psychosomatic Research, 21, 457-461.

StaRR, M. D., \& MineKa, S. (1977). Determinants of fear over the course of avoidance learning. Learning \& Motivation, 4, 332-350.

TsUdA, A., \& HIRAI, H. (1977). Effects of coping responses on chronic stress in rats. Japanese Journal of Psychosomatic Research, 17, 121-129.

UrSIN, H. (1980). Personality, activation and somatic health: A new psychosomatic theory. In S. Levine \& H. Ursin (Eds.), Coping and health. New York: Plenum.

VolPicelli, J. R., Ulm, R. R., \& Altenor, A. (1984). Feedback during exposure to inescapable shocks and subsequent shock-escape performance. Learning \& Motivation, 15, 279-286.

WeinberG, J., ERSKINE, M., \& Levine, S. (1980). Shock-induced fighting attenuates the effects of prior shock experience in rats. Physiology \& Behavior, 25, 9-16.

WeINer, H. (1977). Psychobiology and human disease. New York: Elsevier.

WEISS, J. M. (1968). Effects of coping responses on stress. Journal of Comparative \& Physiological Psychology, 65, 251-260.

WEISs, J. M. (1970). Somatic effects of predictable and unpredictable shock. Psychosomatic Medicine, 32, 397-408.

Weiss, J. M. (1971). Effects of coping behavior with and without a feedback signal on stress pathology in rats. Journal of Comparative \& Physiological Psychology, 77, 22-30.

WEISS, J. M. (1977). Psychological and behavioral influences on gastrointestinal lesions in animal models. In J. D. Maser \& M. E. P. Seligman (Eds.), Psychopathology: Experimental models. San Francisco: Freeman.

Weiss, J. M., Glazer, H. I., Pohorecky, L. A., Brick, J., \& Miller, N. E. (1975). Effects of chronic exposure to stressors on avoidanceescape behavior and on brain norepinephrine. Psychosomatic Medicine, 37, 522-533.

ZIGMOND, M., \& HARVEY, J. (1970). Resistance to central norepinephrine depletion and decreased mortality in rats chronically exposed to electric foot shock. Journal of Neurovisceral Relations, 31, 373-381.

\section{NOTES}

1. We have used the descriptor "negative" in quotation marks because it involves an interpretation. Our interpretation is based here upon the analysis of Coover, Ursin, and Levine (1973), who argue that corticoid level may be taken as an index of stress. Alternatively, it might be considered merely as an index of arousal (Ursin, 1980), and high levels of arousal might not only not be bad, but may be both appropriate and helpful to the animal facing certain challenges.

(Manuscript received March 25, 1985; revision accepted for publication December 26, 1985.) 